\title{
Enhanced the Efficiency of Enzymatic Hydrolysis on Wheat Straw via Freeze-thawing Pretreatment
}

\author{
Jianghong Sun ( $\nabla$ moasun@163.com ) \\ Ministry of Agriculture and Rural Affairs https://orcid.org/0000-0002-4692-8977 \\ Yuanfang Deng \\ Huaiyin Normal University \\ Shaohua Li \\ Ministry of Agriculture and Rural Affairs \\ Wenyong $\mathrm{Xu}$ \\ Ministry of Agriculture and Rural Affairs \\ Guoquan Liu \\ Ministry of Agriculture and Rural Affairs
}

\section{Research Article}

Keywords: wheat straw, freeze-thawing, pretreatment, enzymatic hydrolysis, physicochemical structure

Posted Date: September 7th, 2021

DOI: https://doi.org/10.21203/rs.3.rs-760758/v1

License: (c) (1) This work is licensed under a Creative Commons Attribution 4.0 International License.

Read Full License 


\title{
1 Enhanced the efficiency of enzymatic hydrolysis on \\ 2 wheat straw via freeze-thawing pretreatment
}

\author{
3 Jianhong Sun ${ }^{1,2, \#,}$, Yuanfang Deng ${ }^{3, \#}$, Shaohua $\mathrm{Li}^{1,2}$, Wenyong $\mathrm{Xu}^{1,2}$, Guoquan $\mathrm{Liu}^{1}$ \\ $4 \quad{ }^{1}$ Rural Energy and Environment Agency, Ministry of Agriculture and Rural Affairs, Beijing \\ 5 100125, P.R.CHINA;
}

$6 \quad{ }^{2}$ Key Laboratory of Resource Recycling Technology and Model, Ministry of Agriculture and $7 \quad$ Rural Affairs, Beijing 100125, P.R.CHINA

$8 \quad{ }^{3}$ Jiangsu Key Laboratory for Biomass-based Energy and Enzyme Technology, Huaiyin Normal 9 University, Huai'an, 223300, CHINA

10 * Correspondence: moasun@ 163.com; Tel.: +86 13811385358

11 \# Jianhong Sun and Yuanfang Deng have equal contribution to the work.

Abstract: This research was investigated to enhance the efficiency of enzymatic hydrolysis on 14 wheat straw via freeze-thawing pretreatment, and to find the physicochemical structural changes after this pretreatment. Results show that, this pretreatment enhances the enzymatic hydrolysis efficiency of cellulose and hemicellulose, and hemicellulose is more susceptible to this pretreatment. The highest enzymatic hydrolysis efficiency of cellulose and hemicellulose was $57.06 \%$ and $70.66 \%$ occurred on $-80^{\circ} \mathrm{C}, 24 \mathrm{~h}$ and $-10^{\circ} \mathrm{C}, 24 \mathrm{~h}$ pretreated samples, with an improvement of 2.23 and 3.13 folds of control. SEM images exhibited that transverse cracks appeared before longitudinal cracks as pretreated conditions aggravated, and holes can be found on every sample after this pretreatment. FTIR and XRD analysis implied that freeze-thawing pretreatment had effect both on the crystalline and amorphous regions, and disrupted the hydrogen bonds among them. This study provided a physical pretreatment method to improve the efficiency of enzymatic hydrolysis on wheat straw.

Keywords: wheat straw; freeze-thawing; pretreatment; enzymatic hydrolysis; physicochemical structure 

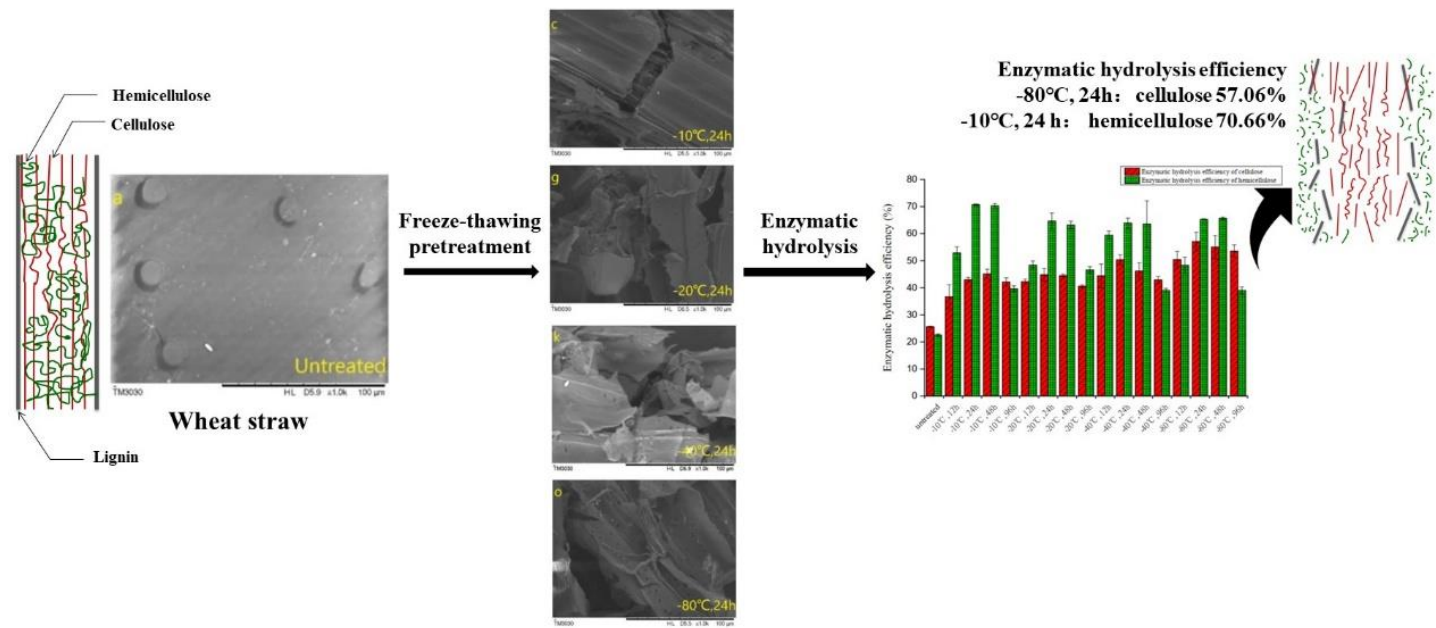

Graphical abstract Freeze-thawing pretreatment enhances the enzymatic hydrolysis efficiency of cellulose and hemicellulose.

\section{Introduction}

Lignocellulosic biomass is an organic material with great potential for renewable energy production by energy conversion (Koupaie et al. 2019). This biomass can be divided into four kinds: agricultural wastes, grasses, hardwood, and softwood (Manisha and Yadav 2017). Agricultural wastes are one of the most widely used lignocellulosic biomass for energy conversion according to former studies and mainly contains wheat straw, barley straw, rice straw, and corn stalks (Jyoti et al. 2019). Three main organic components which are cellulose, hemicellulose and lignin,

still little amounts of minerals, and various extractives and ash consist of lignocellulosic biomass ( $\mathrm{Li}$ et al. 2019c). Cellulose and hemicellulose are polysaccharide polymers, typically make up two-thirds of lignocellulosic biomass (Smichi et al. 2014). Hence they can be used as a substrate to be hydrolyzed by enzymatic treatment to simple sugars then utilized for downstream production ( $\mathrm{Li}$ et al. 2018). Cellulose molecules linked to each other by hydrogen bonds with different orientations resulting in two different structural forms (Kumari and Singh 2018). In amorphous structure, the hydrogen bonds arranged disordered. While the hydrogen bonds packed density highly leading to a crystalline structure which has a high level of crystallinity (Zhao et al. 2017). The crystallinity usually considered as a vital parameter in the 
biodegradation of cellulose, and a higher crystallinity level usually makes it harder to be biodegraded (Sawatdeenarunat et al. 2016). Unlike cellulose, hemicellulose is a heterogeneous polymer contains various polysaccharide (Chen et al. 2017). The monomers of this polysaccharide include hexose (glucose, galactose, and mannose), pentose (xylose and arabinose), deoxyhexose, and some sugar acids (Zheng et al. 2014). Hemicellulose has branches that form strongly with cellulose by hydrogen bonds and lignin by covalent bonds, increasing the difficulties in biodegradation of lignocellulosic biomass (Zhang et al. 2020b). Lignin is a non-polysaccharide component in lignocellulose, which acts as a physical barrier covered on cellulose and hemicellulose (Yang and Pan 2016). In enzymatic hydrolysis of lignocellulosic biomass, lignin also causes nonspecific adsorption of cellulose enzymes, which leads to the low efficiency of enzymatic hydrolysis (Koupaie et al. 2019).

The complexity of these components creates resistance to biological degradation and significantly reduces its accessibility to cellulose degrading enzymes (Zhang et al. 2020a). Hence, a pretreatment step is essential to enhance the efficiency of enzymatic hydrolysis by mechanical, physicochemical, chemical or biological pretreatment method (Wang et al. 2019). These methods aim to increase the accessibility of cellulose by destroying the complete structure of biomass, breaking the physical barriers of lignin, and reducing the proportion of crystalline area of cellulose (Kainthola et al. 2019).

Freeze-thawing pretreatment is an efficient mechanical method leading to the disruption of biomass (Liu et al. 2020), thus an increase in cellulose accessibility. Water converts into ice front which acts as a cutting tool causing the damage of biomass structure. Furthermore, the expanding of water increases the specifical surface areas and pore size of biomass, which enhances the ruin (Wang et al. 2001). Rempel et al. (2018) use freeze-thawing, ultrasound, gelatinization and autoclaving as a physical method of achieving cell wall disruption and releasing intracellular polysaccharides of Spirulina biomass. After cell rupture, enzymatic saccharification was conducted to evaluate which method is more effective in releasing carbohydrates. The scholar pointed that freeze-thawing is the best condition of cell rupture of Spirulina biomass. Qi et al. (2020) obtained the total reducing sugar (TRS) yields from peanut shell powers with temperature pretreatment from -80 to $100^{\circ} \mathrm{C}$. The scholar observed that, the TRS yield increased nearly twice of that at raw peanut shell powers after heat pretreatment, and 
1.7 folds after freeze-thawing pretreatment. Although the enhancement seems similar by these two methods, the author emphasized that, at higher heating temperature, the oligomeric and monomeric sugars from peanut shell powers were further degraded into inhibitors, such as furfural, that reduced the recovery of hemicellulose. Further separation is required, which increases investment (Wang et al. 2018). However, freeze-thawing pretreatment contains a freezing process of interlayer water and crystal water in peanut shell powers, in which furfural will not be produced.

Though, freeze-thawing pretreatment is confirmed that it can be performed on several kinds of biomass such as waste activated sludge, food waste and microalgal biomass for energy production (Gruber-Brunhumer et al. 2016; Karthikeyan et al. 2018; Liu et al. 2020). And has advantages of no chemical additives, no inhibition generation and no pollution. The application of this method on low water content lignocellulosic biomass is still small, the effect on them to energy production is less known, and mechanism of it still needs to be further studied.

The present study was designed to investigate the influence of freeze-thawing pretreatment on wheat straw (WS). Examining the reducing sugar yields after enzymatic hydrolysis to evaluate the efficiency of this method. To further explore the interaction between reducing sugar releasing and the structure change, several characteristic techniques were analyzed. These techniques include SEM, FTIR and XRD, assisting us in revealing surface morphology and inner ultrastructure change corresponding to this mechanical pretreatment.

\section{Materials and Methods}

\subsection{Raw biomass}

Wheat straw was harvested in Northwest A\&F University, air dried, milled and sieved to 20 mesh. After then wheat straw was dried at $55^{\circ} \mathrm{C}$ until constant weight and stored in sealed bags for later use. The total solid (TS), volatile solid (VS) of untreated wheat straw in this study was $96.43 \pm 0.17 \%$ and $87.64 \pm 0.21 \%$. And the untreated wheat straw consists of $31.66 \pm 0.76 \%$ cellulose, $26.44 \pm 1.69 \%$ hemicellulose and $20.91 \pm 0.17 \%$ klason lignin.

Commercial cellulase was purchased from Shanghai Yuanye Bio-Technology Co., Ltd, $\beta$ glucosidase was purchased from Sigma-Aldrich (Shanghai, China). One unit of filter paper activity of cellulase was determined as the amount of enzyme assumed $50 \mathrm{mg}$ filter paper and 
produced $2.0 \mathrm{mg}$ reducing sugar in 1 hour, measured according to the standard established by the National Renewable Energy Laboratory (Adney and Baker 1996).

\subsection{Pretreatment of wheat straw}

Wheat straw used in this study suffered different freezing time and freezing temperature pretreatment. After being soaked at room temperature for 8 hours with solid to liquid ratio of $1: 8 \mathrm{w} / \mathrm{w}$ (VS), samples were put into different refrigerators of $-10^{\circ} \mathrm{C},-20^{\circ} \mathrm{C},-40^{\circ} \mathrm{C}$ and $-80^{\circ} \mathrm{C}$, and frozen for $12 \mathrm{~h}, 24 \mathrm{~h}, 48 \mathrm{~h}$ and $96 \mathrm{~h}$, respectively. Every sample was thawed at room temperature for 8 hours after taken out, then filtered by a suction flask, dried then kept in sealed bags for enzymatic hydrolysis.

\subsection{Enzymatic hydrolysis}

Enzymatic hydrolysis was conducted in $125 \mathrm{~mL}$ conical flasks with solid loading of $2 \%(\mathrm{w} / \mathrm{v})$. Commercial cellulase and $\beta$-glucosidase were added into each flask with $20 \mathrm{FPU} / \mathrm{g}$ substrate and $40 \mathrm{CBU} / \mathrm{g}$ substrate, respectively. Hydrolysis was carried out with $0.05 \mathrm{M}$ sodium citrate buffer $\left(\mathrm{pH} 4.8\right.$ ) at $50^{\circ} \mathrm{C}$ for $72 \mathrm{~h}$, with a rotator of $150 \mathrm{rpm} / \mathrm{min}$. To prevent the growth of organisms, $200 \mathrm{mg} / \mathrm{L}$ sodium azide was added to samples. Wheat straw without any pretreatment was conducted as control. All experiments were performed in triplicate.

\subsection{Detection of reducing sugars}

Reducing sugar was detected by high-performance anion exchange chromatography (HPAEC) (Dionex, ICS-5000) equipped with a CarboPac PA-10 analytical column. Mobile phase is $200 \mathrm{mM}$ and $18 \mathrm{mM} \mathrm{NaOH}$ at $1.0 \mathrm{~mL} / \mathrm{min}$ with column temperature of $30^{\circ} \mathrm{C}$ and detection cell temperature of $25^{\circ} \mathrm{C}$. The enzymatic hydrolysis efficiency of cellulose and hemicellulose were calculated by Eqs. (1) and (2) (Li et al. 2019a):

Enzymatic hydrolysis efficiency of cellulose $(\%)$

$=\frac{c_{\text {glucose }} \times 0.9}{c_{\text {substrate }} \times \text { cellulose content in substrate }} \times 100$

Enzymatic hydrolysis efficiency of hemicellulose (\%) 
$131=\frac{c_{x y l o s e} \times 0.88}{c_{\text {substrate }} \times \text { hemicellulose content in substrate }} \times 100$

132

where $c_{\text {substrate }}$ is the substrate loading, $\mathrm{g} / \mathrm{L}, c_{x y l o s e}$ and $c_{\text {glucose }}$ are the xylose and glucose content in hydrolysate, $\mathrm{g} / \mathrm{L}$.

\subsection{Lignocellulose composition analysis}

The lignocellulose composition of wheat straw was measured by fiber analyzer A200i (ANKOM Co., US). Acid detergent fiber (ADF), neutral detergent fiber (NDF), residue after $72 \% \mathrm{H}_{2} \mathrm{SO}_{4}$ treatment, and acid detergent lignin (ADL) were determined to calculate the contents of cellulose, hemicellulose and lignin. Calculation equations as follow:

Hemicellulose $(\%)=\mathrm{NDF} \%-\mathrm{ADF} \%$

$\operatorname{Lignin}(\%)=$ ADL $\%$

Cellulose $(\%)=\mathrm{ADF} \%-$ Residue after $72 \% \mathrm{H}_{2} \mathrm{SO}_{4}$

\section{6. $X$-ray diffraction $(X R D)$}

X-ray diffraction was performed to measure crystallinity index using a Bruker D8ADVANCE XRD instrument (Bruker AXS Inc. Karlsruhe, Germany) with nickel filtered Cu$\mathrm{k} \alpha$ (wavelength $1.5418 \AA$ radiation) at $40 \mathrm{kV}$ and $40 \mathrm{~mA}$. The diffractograms were collected from $4^{\circ}$ to $45^{\circ}$ with incremental steps of 0.02 . The crystallinity index was calculated as follows (Segal et al. 1959):

Crystallinity index $(C r I)=\frac{I_{002}-I_{a m}}{I_{002}} \times 100 \%$

where $I_{002}$ is the diffraction intensity of the crystalline regions, $2 \theta=22.5^{\circ}$ and $I_{a m}$ is the diffraction intensity of amorphous regions, $2 \theta=18.5^{\circ}$.

2.7. Fourier transform infrared spectroscopy (FTIR)

FTIR spectroscopy analysis was analyzed using a Vertex 70 (Bruker AXS Inc. Karlsruhe, Germany). Samples were mixed with $\mathrm{KBr}$ of 1:100, and pressed to disks at $25 \mathrm{Mpa}$. Spectra 
was detected from 4000 to $400 \mathrm{~cm}^{-1}$ at 32 scans. The background spectrum of pure $\mathrm{KBr}$ was subtracted from the sample spectrum.

\subsection{Scanning electron microscopy (SEM)}

Morphology analysis of samples was observed by Model S-3400N scanning electron microscope (Hitachi, Japan).

\subsection{Statistical analysis}

Statistical analysis of the data and graphing were finished by Origin Pro 9.1 (Origin Lab, USA). The experimental data were analyzed by analysis of variance (ANOVA) for Fisher's least significant difference (LSD) analysis ( $\mathrm{p}<0.05)$.

\section{Results}

\subsection{Chemical composition}

The composition of wheat straw (WS) was measured to find the chemical changes after freeze-thawing (FT) pretreatment. Untreated wheat straw consists of $31.66 \pm 0.76 \%$ cellulose, $26.44 \pm 1.69 \%$ hemicellulose and $20.91 \pm 0.17 \%$ klason lignin. As shown in Table 1 , both pretreated factors of freezing time and freezing temperature have no significant influence on the decomposition of WS ( $\mathrm{p}<0.05)$. Cellulose has improved most among the three composition, and the highest content of it occurs on $-80^{\circ} \mathrm{C}, 24 \mathrm{~h}$ pretreated WS, which is $33.49 \pm 1.7 \%$. Lignin is the most stable composition without any change after pretreatment $(\mathrm{p}<0.05)$. The stubborn barrier of it is one of the reasons that hydrolysis is inefficient and pretreatment is necessary to open the tight structure. The content of hemicellulose has a slight decrease at the 96-h pretreated group, while this mere decline can be ignored $(\mathrm{p}<0.05)$. The tiny change in composition suggests that FT has no effect on the degradation of chemical components. This result confirms that FT is a physical pretreatment method and has a similar effect on biomass as other physical methods do like milling (Jiang et al. 2017). Li et al. (2019b) tested three main components every seven day on natural freeze-thawing pretreated corn straw, and got that they are basically constants during 28-d pretreated period. 
181 The composition of wheat straw

\begin{tabular}{llll}
\hline Pretreatment Condition & Cellulose $\%$ & Hemicellulose $\%$ & Lignin \% \\
\hline untreated & $31.66 \pm 0.76$ & $26.44 \pm 1.69$ & $20.91 \pm 0.17$ \\
$-10^{\circ} \mathrm{C}, 12 \mathrm{~h}$ & $32.34 \pm 0.29$ & $27.40 \pm 0.90$ & $20.60 \pm 0.97$ \\
$-10^{\circ} \mathrm{C}, 24 \mathrm{~h}$ & $32.66 \pm 1.35$ & $27.24 \pm 0.59$ & $20.56 \pm 1.85$ \\
$-10^{\circ} \mathrm{C}, 48 \mathrm{~h}$ & $33.06 \pm 3.04$ & $27.34 \pm 0.42$ & $20.50 \pm 2.28$ \\
$-10^{\circ} \mathrm{C}, 96 \mathrm{~h}$ & $32.33 \pm 0.71$ & $26.90 \pm 0.67$ & $20.46 \pm 0.24$ \\
$-20^{\circ} \mathrm{C}, 12 \mathrm{~h}$ & $32.38 \pm 1.08$ & $27.13 \pm 1.00$ & $20.56 \pm 0.90$ \\
$-20^{\circ} \mathrm{C}, 24 \mathrm{~h}$ & $32.36 \pm 1.82$ & $27.65 \pm 0.28$ & $20.58 \pm 1.26$ \\
$-20^{\circ} \mathrm{C}, 48 \mathrm{~h}$ & $32.51 \pm 1.71$ & $27.19 \pm 1.31$ & $20.58 \pm 1.91$ \\
$-20^{\circ} \mathrm{C}, 96 \mathrm{~h}$ & $32.31 \pm 1.32$ & $26.92 \pm 0.77$ & $20.31 \pm 0.92$ \\
$-40^{\circ} \mathrm{C}, 12 \mathrm{~h}$ & $32.27 \pm 3.57$ & $27.70 \pm 2.08$ & $20.67 \pm 0.80$ \\
$-40^{\circ} \mathrm{C}, 24 \mathrm{~h}$ & $33.05 \pm 1.58$ & $27.62 \pm 0.49$ & $20.57 \pm 1.52$ \\
$-40^{\circ} \mathrm{C}, 48 \mathrm{~h}$ & $32.70 \pm 1.55$ & $27.01 \pm 2.46$ & $20.62 \pm 2.73$ \\
$-40^{\circ} \mathrm{C}, 96 \mathrm{~h}$ & $32.53 \pm 0.18$ & $26.81 \pm 0.59$ & $20.84 \pm 0.48$ \\
$-80^{\circ} \mathrm{C}, 12 \mathrm{~h}$ & $33.23 \pm 2.98$ & $27.17 \pm 1.52$ & $20.57 \pm 1.82$ \\
$-80^{\circ} \mathrm{C}, 24 \mathrm{~h}$ & $33.49 \pm 1.70$ & $27.66 \pm 1.44$ & $20.56 \pm 1.09$ \\
$-80^{\circ} \mathrm{C}, 48 \mathrm{~h}$ & $32.94 \pm 2.18$ & $27.56 \pm 1.86$ & $20.76 \pm 1.32$ \\
$-80^{\circ} \mathrm{C}, 96 \mathrm{~h}$ & $32.82 \pm 0.56$ & $26.84 \pm 1.03$ & $20.53 \pm 1.14$ \\
\hline
\end{tabular}

Note. All data in the table represent mean value \pm SD based on three replicates.

\subsection{Enzymatic hydrolysis}

Detect reducing sugar releasing, mainly glucose and xylose to evaluate the efficiency of enzymatic hydrolysis. These two reducing sugars are the typical component of cellulose and hemicellulose, which is the indicators for the enzymatic hydrolysis efficiency of cellulose and hemicellulose, respectively. It is obvious that the efficiency of both cellulose and hemicellulose is largely improved after FT as shown in Figure 1. This finding is similar with former study on FT pretreated peanut shell (Qi et al. 2020). The enzymatic hydrolysis efficiency of cellulose on untreated WS is $25.63 \%$ after $72 \mathrm{~h}$ enzymatic hydrolysis. As the freezing temperature drops, the enzymatic hydrolysis efficiency of cellulose on WS improves steadily in the same freezing time pretreated group. In $24 \mathrm{~h}$ pretreated group, the enzymatic hydrolysis efficiency of cellulose is $42.99 \%, 44.77 \%, 50.33 \%$ and $57.06 \%$ for $-10^{\circ} \mathrm{C},-20^{\circ} \mathrm{C},-40^{\circ} \mathrm{C}$ and $-80^{\circ} \mathrm{C}$ pretreated WS, respectively, with the improvement of $67.73 \%, 74.68 \%, 96.37 \%$ and $122.63 \%$ comparing with untreated WS. This group shows the largest enhancement among four experimental groups of different freezing time. While in the group of same freezing temperature pretreated sample, the enzymatic hydrolysis efficiency of cellulose shows an up and down trend as the function of 
freezing time. Take $-80^{\circ} \mathrm{C}$ pretreated group for example, the enzymatic hydrolysis efficiency of cellulose in this group is $50.42 \%, 57.06 \%, 55.03 \%$ and $53.54 \%$ for $12 \mathrm{~h}, 24 \mathrm{~h}, 48 \mathrm{~h}$ and $96 \mathrm{~h}$, respectively. This freezing temperature also shows great progress among four experimental groups, with an improvement of $96.72 \%, 122.63 \%, 114.71 \%$ and $108.90 \%$. It can be found that the largest improvement in the enzymatic hydrolysis efficiency of cellulose was on $-80^{\circ} \mathrm{C}, 24$ h pretreated WS, nearly 2.23 folds of untreated WS.

Under the same experimental condition of freezing temperature, the enzymatic hydrolysis efficiency of hemicellulose exhibits the similar trend as cellulose, which is up and down as the function of freezing time while still higher than untreated WS. Considering the slight decline in the enzymatic hydrolysis efficiency of cellulose and hemicellulose at severity stage, the possible reason is that, the damage in freezing stage causes soluble organics releasing in the liquid phase and washed away in thawing stage (Liu et al. 2020).

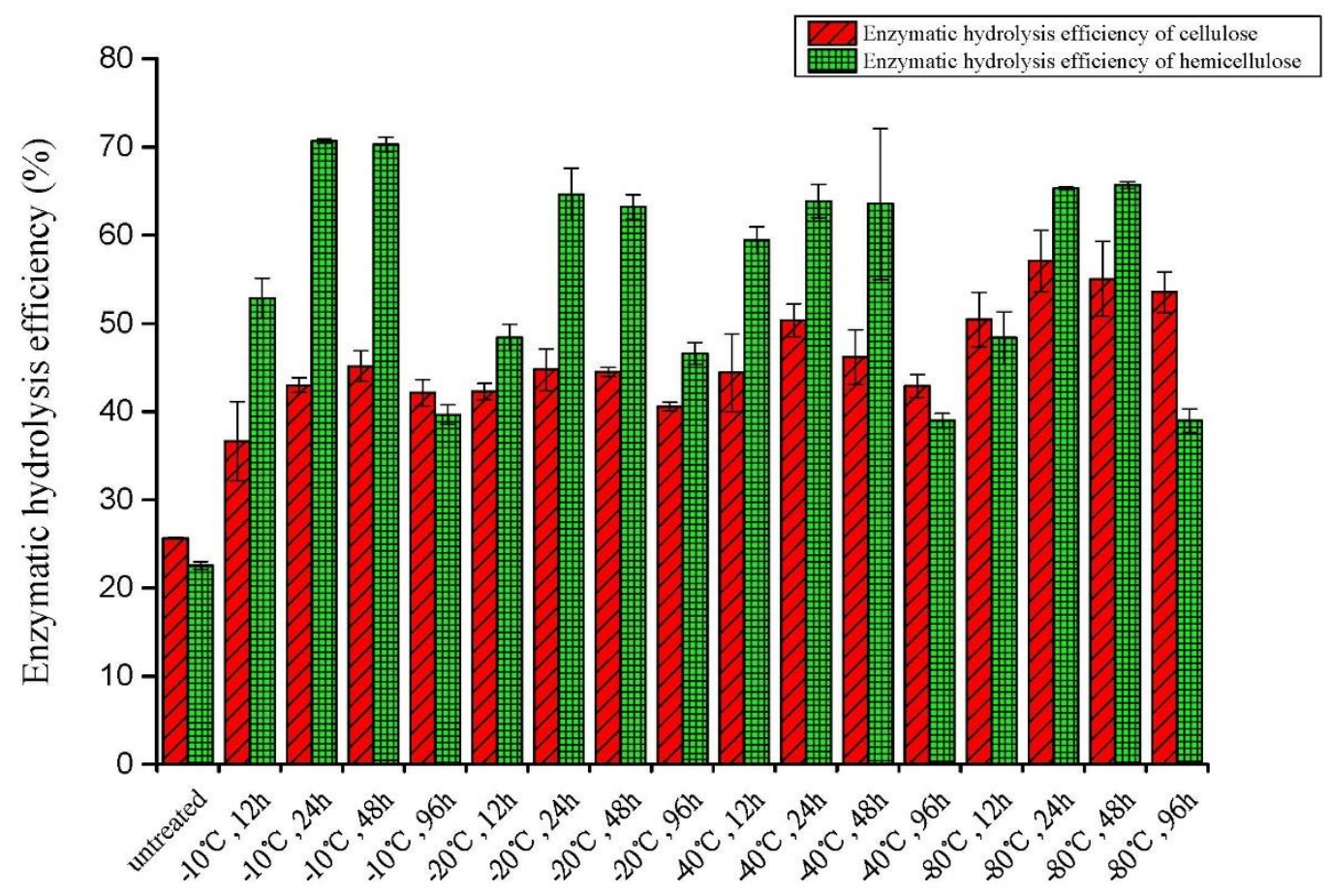

Fig. 1. Enzymatic hydrolysis efficiency of wheat straw under different conditions.

Though, the influence on the increase of efficiency and the variation trend of rise then descent is similar, there exists some differences. Firstly, the maximum improvement on the enzymatic hydrolysis efficiency of cellulose has been increased by 2.23 times, and that of hemicellulose is 3.13 times. It suggests that, FT pretreatment has more influence on hemicellulose than 
cellulose. Secondly, the highest improvement on cellulose was obtained under $-80^{\circ} \mathrm{C}, 24 \mathrm{~h}$ condition, compared with the highest improvement obtained from hemicellulose under $-10^{\circ} \mathrm{C}$, $24 \mathrm{~h}$ condition. Besides, the improvements in the enzymatic hydrolysis efficiency of cellulose are all lower than hemicellulose under the same circumstance except $-80^{\circ} \mathrm{C}, 96 \mathrm{~h}$ condition. This implies that, hemicellulose is much easier to be degraded than cellulose. Finally, though both of the variation trends climb and fall, the change range on the enzymatic hydrolysis efficiency of hemicellulose is obviously boarder than that of cellulose. The maximum amplitude on the enzymatic hydrolysis efficiency of cellulose ranging from $36.65 \%-45.12 \%$ in $-10^{\circ} \mathrm{C}$ pretreatment group, with the highest improvement of $23.11 \%$. In comparison, the maximum amplitude on the enzymatic hydrolysis efficiency of hemicellulose ranging from $39.62 \%-70.66 \%$ in $-10^{\circ} \mathrm{C}$ pretreatment group, with the highest improvement of $78.34 \%$. It seems that, hemicellulose is more sensitive than cellulose to the effect of freeze-thawing pretreatment, and easier to be degraded. This finding is corresponding to what happened on rice hull after extrusion treatment obtained by Zhang et al. (2020b). Hemicellulose is known as a kind of polysaccharide with a lower degree of polymerization and amorphous structure, hence makes hemicellulose relatively vulnerable to be degraded than cellulose (Sawatdeenarunat et al. 2016).

\subsection{Structural characterization}

\subsubsection{X-ray Diffraction (XRD)}

Cellulose contains crystalline and amorphous regions, and the crystal is considered as an obstacle for enzymatic hydrolysis (Sindhu et al. 2016). All samples exhibit a same shape in XRD pattern, which means there is no chemical structure change during FT pretreatment (Li et al. 2019a). Figure 2 shows part of patterns of experimental samples, it seems that, the diffraction pattern of FT pretreated WS is plainer than untreated WS. Further, crystallinity index (CrI) was calculated according to Segal method to quantify this change. Higher CrI means more regions in crystal and is difficult in enzymatic hydrolysis ( $\mathrm{Ji}$ et al. 2016). The CrI of untreated WS is $64.78 \%$, and the value decreases steadily as FT pretreatment condition aggrieves. This result is in accordance with (Jiang et al. 2017), who got a drop of CrI on wood cellulose after balling 

(2017) also found an obvious decrease in CrI of starch after FT pretreatment.

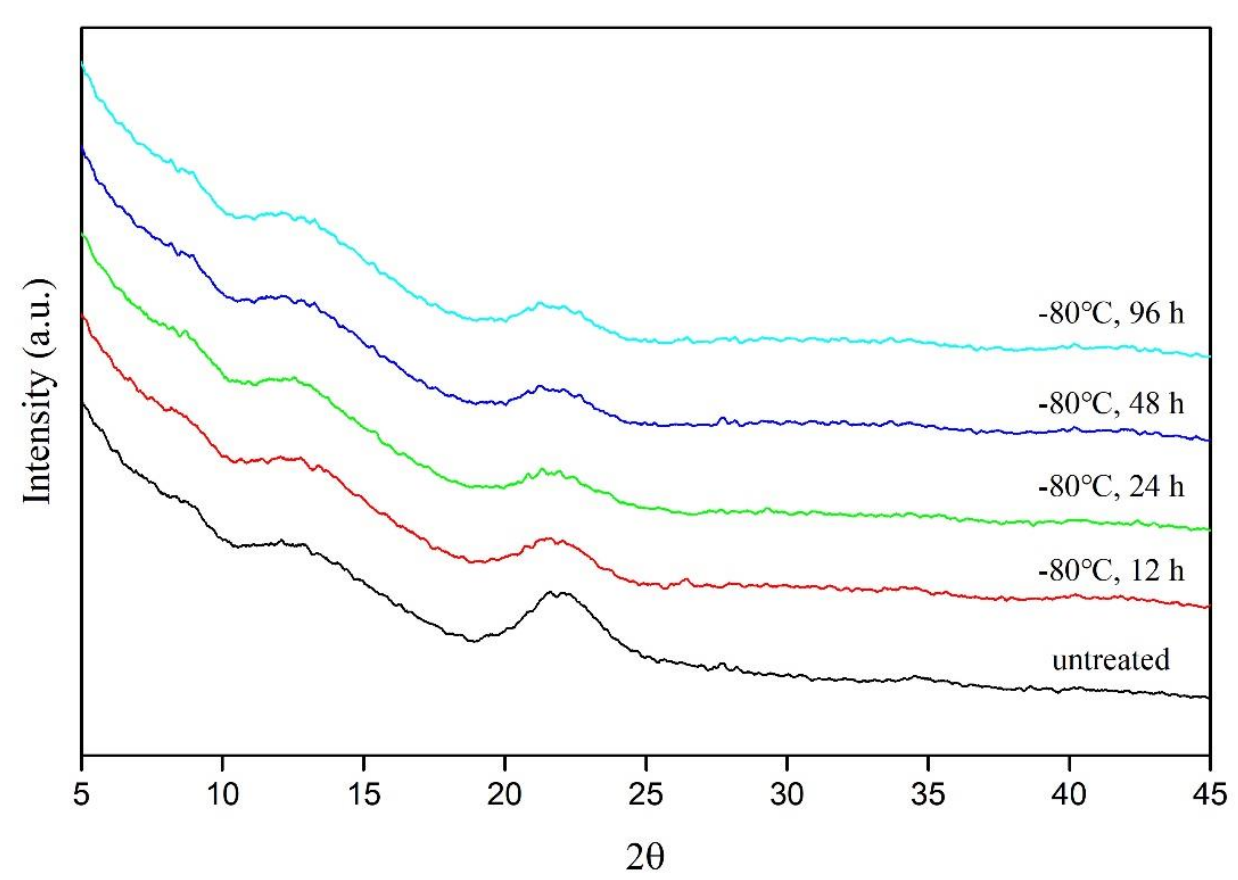

pretreatment, and the dropping trend is similar with what obtained in this study. Zhao et al.

Fig. 2. XRD pattern of wheat straw under different conditions.

This phenomenon owing to the ice force caused by FT, which disrupts the crystalline order, causing the destruction of crystalline regions then the decrease in crystallinity (Zhao et al. 2018). Under mild conditions, the decline of $\mathrm{CrI}$ is not significant for $61.49 \%$ on $-10^{\circ} \mathrm{C}, 12 \mathrm{~h}$ pretreated WS. As the pretreated condition aggravates, the value of CrI shows an indirect proportion with pretreated conditions. The lowest CrI occurred on $-80^{\circ} \mathrm{C}, 96 \mathrm{~h}$ pretreated WS with $51.98 \%$, which is nearly $13 \%$ drop in this index. This finding indicates that FT pretreatment irreversibly disrupts the crystalline order of cellulose.

\subsubsection{Fourier transform infrared (FTIR)}

All samples exhibit a same wave spectrum in FTIR, indicating that FT pretreatment is useless to chemical structure in WS. Typical spectrums were selected and drawn in Figure 3. 


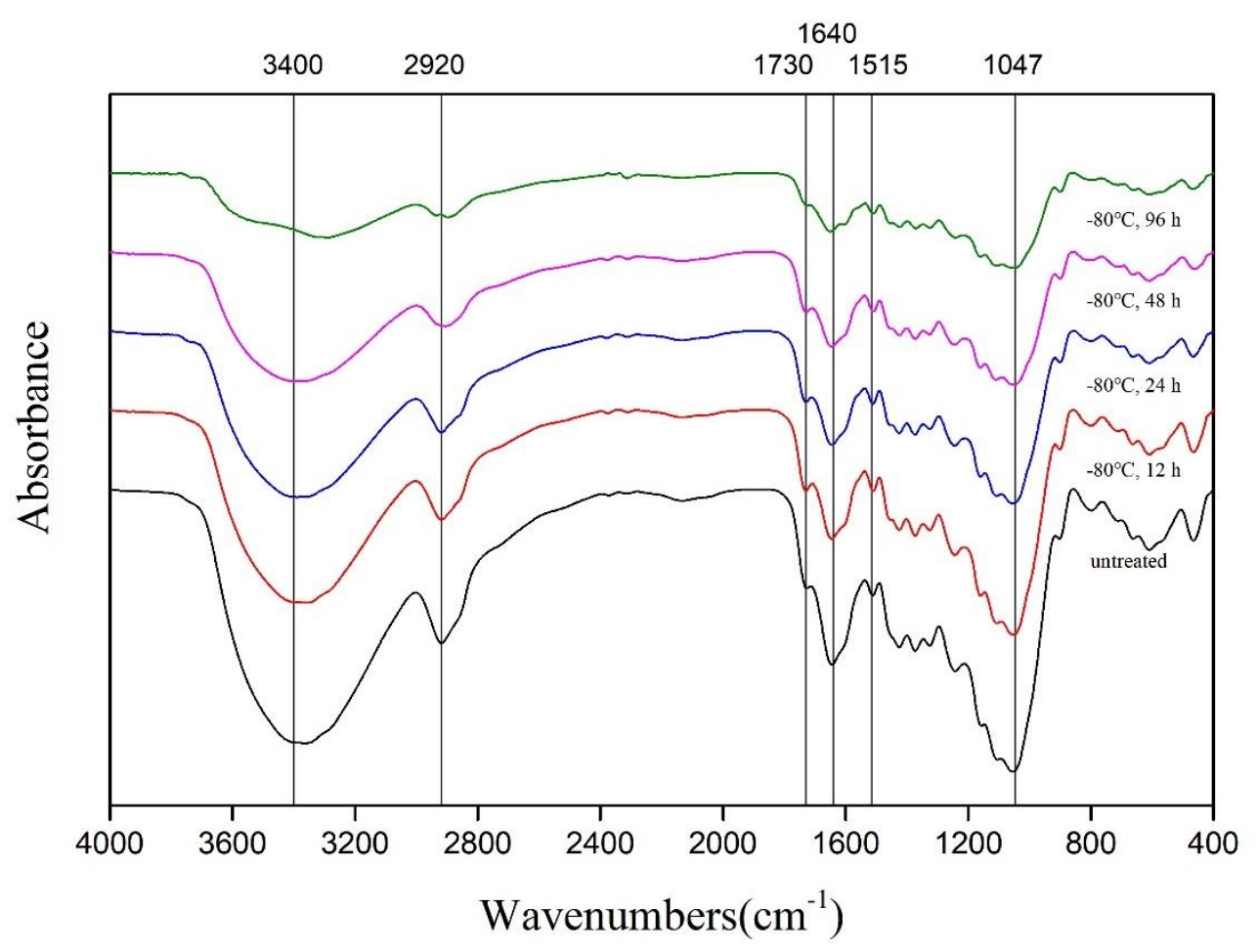

Fig. 3. FTIR spectrum of wheat straw under different conditions.

Several obvious weaknesses of stretching or bending vibration can be found in 3400, 2920 , $1730,1625,1515$ and $1047 \mathrm{~cm}^{-1}$. The peak at $3400 \mathrm{~cm}^{-1}$ is responding for $-\mathrm{OH}$ stretching vibration in cellulose. Boarder and weaker absorption range show that FT ruptured intramolecular hydrogen bonds in cellulose (Li and Renneckar 2011). Hydrogen bonds exiting both inter and intra is one of the reasons that can cause the ineffectively in enzymatic hydrolysis. Disturbing part of hydrogen bonds increases the accessibility of substrate thus enhances the hydrolysis of cellulose (Ji et al. 2016). The peak at $2920 \mathrm{~cm}^{-1}$ relating to the stretching of $-\mathrm{CH}_{2}$ in cellulose, can be found weaker as pretreated condition aggravates. This stretching vibration of $-\mathrm{CH}_{2}$ is believed to have a relationship with crystal structure in cellulose ( $\mathrm{Li}$ and Renneckar 2011). It is reported that the peak at $1730 \mathrm{~cm}^{-1}$ was represented to the stretching of $\mathrm{C}-\mathrm{O}$ ester in acetyl groups linked to hemicellulose ( $\mathrm{Li}$ et al. 2019a). An obvious change occurred on peak $1640 \mathrm{~cm}^{-1}$ is associated with absorbed water in the structure of cellulose. According to the literature, this band is associated with the bending modes of water molecules due to a strong interaction between cellulose and water (Haafiz et al. 2014). The absorption peak at $1515 \mathrm{~cm}^{-1}$ is bond to the stretching or bending vibration for aromatic rings of lignin, and does not show a clear change. The absorption peak at $1047 \mathrm{~cm}^{-1}$ representing the stretching vibration of C-O is the characteristic of crystalline structures in polysaccharide (Zhao et al. 2018). The weaker 
vibration especially those related to cellulose shown on spectrum implies that, mechanical force caused by FT does not change the properties of WS except the hydrogen bonds associated with the crystal and amorphous structure of experimental samples. Relating what obtained from XRD above, it can be implied that mechanical damage caused by the formation of ice crystals is random and occurs in both the crystalline and amorphous regions.

\subsubsection{Scanning electron microscopy (SEM)}

Figure 4 displays a clear image of all WS. As can be seen from untreated WS, the surface is smooth, waxy and compact, and the cylindrical bulge of silica particles can also be found layout densely. After FT pretreatment, all WS shows disrupt to different extents. Under low treated circumstances, transverse cracks occur on the surface firstly, superficial and distributing along with the bulge, going deep and becoming board later. Then, longitudinal cracks turn up which is smaller, shorter yet seems deeper than transverse crack and the intact surface is no longer visible. As pretreated condition severity, cracks show a distribution of high density, and straw breaks down into pieces while still layout in order. Meantime, small holes are found on straw, showing a trend of larger diameter and more intensively as pretreated condition enhanced. Under the severest pretreated circumstance, the fragments are unordered, and the structure of WS even could not be identified. After FT pretreatment, all experimental samples have a higher specific surface area (SSA) due to the holes and the smaller fragments caused by ice crystals. The disappearance of waxy skin also relieved the barriers for enzyme attaching the substrate. Above all, FT pretreatment improves SSA resulting in a higher efficiency of reducing sugar. During freezing phase, water around biomass is frozen to ice, which acts as a cutting tool, caused cracks and fragments on straw. Besides, as the water is frozen to ice, the volume becomes larger, the ice in the biomass can burst the structure of biomass and left holes after thawing [34]. 


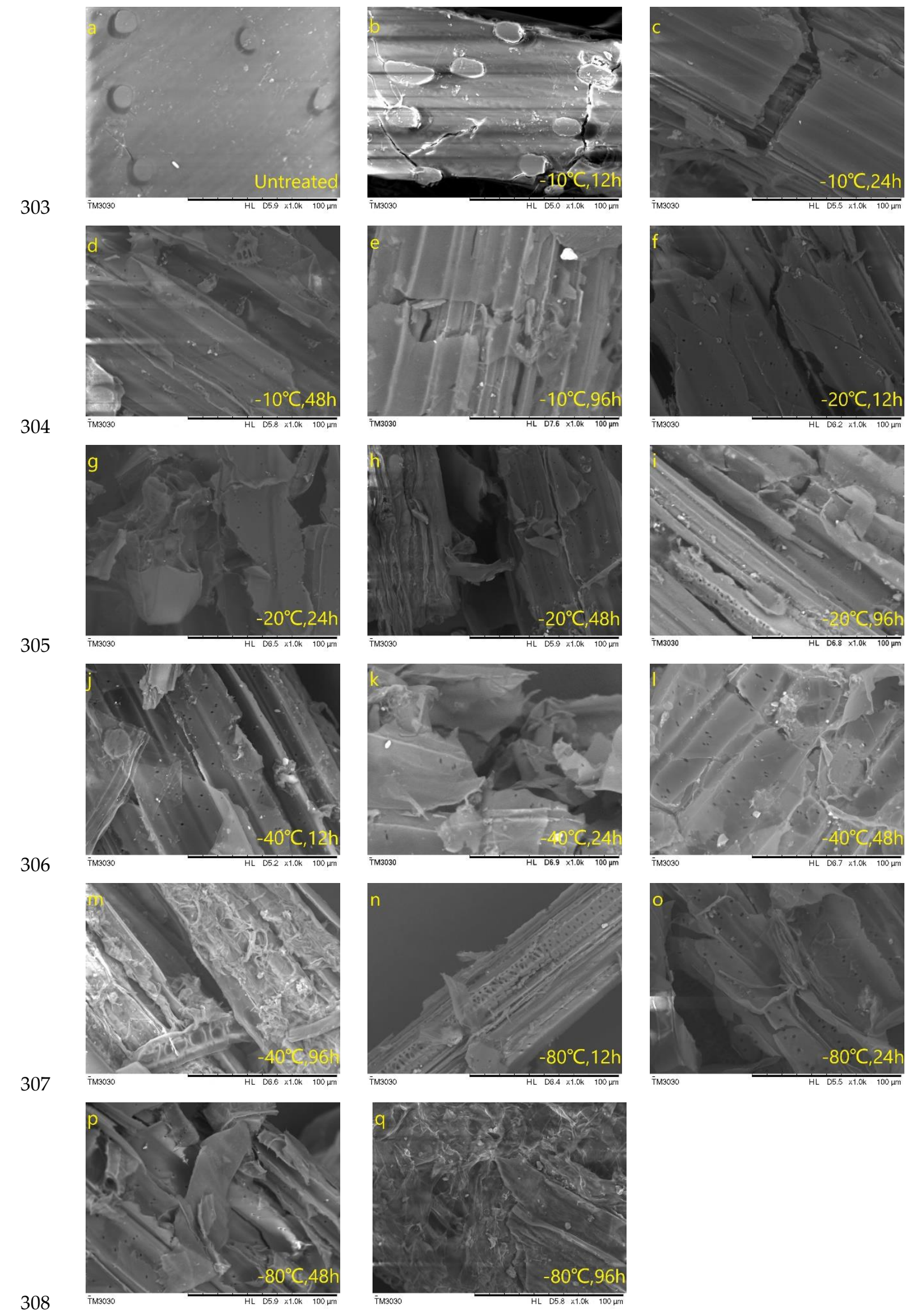

Fig. 4. SEM of wheat straw under different conditions. 


\section{Conclusions}

Freeze-thawing pretreatment is an efficient method in increasing enzymatic hydrolysis of wheat straw. The enzymatic hydrolysis efficiency of cellulose enhances from $25.64 \%$ to 57.06 $\%$, and the enzymatic hydrolysis efficiency of hemicellulose increases from $22.55 \%$ to 70.66 $\%$. The enhancements attributed to the fact that this pretreatment loosens wheat straw compact structure showing transverse and longitudinal cracks on surface, increases its pores size, destroys its crystalline regions and hydrogen bonds. This pretreatment can occur naturally in cold areas without additional energy input. Thus, it can be defined as a green method for lignocellulose biomass pretreatment of enzymatic hydrolysis.

Acknowledgments: This work was given comments from Prof. Yiqing Yao works at Northwest A\&F University.

Availability of data and materials: The datasets used and/or analyzed during the current study are available from the corresponding author on reasonable request.

Author Contributions: Conceptualization, Jianhong Sun; methodology, Yuanfang Deng; software, Jianhong Sun; validation, Jianhong Sun; formal analysis, Jianhong Sun; investigation, Yuanfang Deng; resources, Shaohua Li; data curation, Jianhong Sun; writing—original draft preparation, Jianhong Sun; writing - review and editing, Wenyong Xu; visualization, Guoquan Liu; supervision, Guoquan Liu; project administration, Guoquan Liu; funding acquisition, Guoquan Liu.

Funding: This research work was supported by the National Key Research and Development Program (2016YFD0501403).

\section{Declarations}

\section{Ethical approval: Not applicable}

Consent to participate: I am free to contact any of the people involved in the research to seek further clarification and information.

Consent for publication: Not applicable

Competing Interests: The authors declare that they have no conflict of interest. 


\section{References}

Adney B, Baker J (1996) Measurement of Cellulase Activities. Laboratory Analytical Procedure 6:1-8 Chen $\mathrm{H}$ et al. (2017) A review on the pretreatment of lignocellulose for high-value chemicals. Fuel Processing Technology 160:196-206 doi:10.1016/j.fuproc.2016.12.007

Gruber-Brunhumer MR et al. (2016) Associated effects of storage and mechanical pre-treatments of microalgae biomass on biomethane yields in anaerobic digestion. Biomass and Bioenergy 93:259-268 doi:10.1016/j.biombioe.2016.07.013

Haafiz MKM, Hassan A, Zakaria Z, Inuwa IM (2014) Isolation and characterization of cellulose nanowhiskers from oil palm biomass microcrystalline cellulose. Carbohyd Polym 103:119-125 doi:https://doi.org/10.1016/j.carbpol.2013.11.055

Ji G, Gao C, Xiao W, Han L (2016) Mechanical fragmentation of corncob at different plant scales: Impact and mechanism on microstructure features and enzymatic hydrolysis. Bioresour Technol 205:159-165 doi:10.1016/j.biortech.2016.01.029

Jiang J, Wang J, Zhang X, Wolcott M (2017) Assessing multi-scale deconstruction of wood cell wall subjected to mechanical milling for enhancing enzymatic hydrolysis. Industrial Crops Products 109:498-508

Jyoti K, Kalamdhad AS, Goud VV, Goel R (2019) Fungal pretreatment and associated kinetics of rice straw hydrolysis to accelerate methane yield from anaerobic digestion. Bioresour Technol 286:121368 doi:https://doi.org/10.1016/j.biortech.2019.121368

Kainthola J, Shariq M, Kalamdhad AS, Goud VV (2019) Enhanced methane potential of rice straw with microwave assisted pretreatment and its kinetic analysis. J Environ Manage 232:188-196 doi:10.1016/j.jenvman.2018.11.052

Karthikeyan OP, Trably E, Mehariya S, Bernet N, Wong JWC, Carrere H (2018) Pretreatment of food waste for methane and hydrogen recovery: A review. Bioresour Technol 249:1025-1039 doi:https://doi.org/10.1016/j.biortech.2017.09.105

Koupaie EH, Dahadha S, Bazyar Lakeh AA, Azizi A, Elbeshbishy E (2019) Enzymatic pretreatment of lignocellulosic biomass for enhanced biomethane production-A review. J Environ Manage 233:774-784 doi:10.1016/j.jenvman.2018.09.106

Kumari D, Singh R (2018) Pretreatment of lignocellulosic wastes for biofuel production: A critical review. Renewable and Sustainable Energy Reviews 90:877-891 doi:https://doi.org/10.1016/j.rser.2018.03.111

Li H et al. (2019a) Enhanced enzymatic hydrolysis of wheat straw via a combination of alkaline hydrogen peroxide and lithium chloride/N,N-dimethylacetamide pretreatment. Industrial Crops and Products 137:332-338 doi:10.1016/j.indcrop.2019.05.027

Li J, Wachemo AC, Yuan H, Zuo X, Li X (2019b) Natural freezing-thawing pretreatment of corn stalk for enhancing anaerobic digestion performance. Bioresour Technol 288:121518 doi:10.1016/j.biortech.2019.121518

Li Q, Renneckar S (2011) Supramolecular Structure Characterization of Molecularly Thin Cellulose I Nanoparticles. Biomacromolecules 12:650-659 doi:10.1021/bm101315y

Li Y, Chen Y, Wu J (2019c) Enhancement of methane production in anaerobic digestion process: A review. Applied Energy 240:120-137 doi:10.1016/j.apenergy.2019.01.243

Li Y, Zhang Z, Zhu S, Zhang H, Zhang Y, Zhang T, Zhang Q (2018) Comparison of bio-hydrogen production yield capacity between asynchronous and simultaneous saccharification and 
fermentation processes from agricultural residue by mixed anaerobic cultures. Bioresource Technology 247:1210 - 1214 doi:https://doi.org/10.1016/j.biortech.2017.09.053

Liu XR et al. (2020) Activation of nitrite by freezing process for anaerobic digestion enhancement of waste activated sludge: Performance and mechanisms. Chemical Engineering Journal 387 doi:https://doi.org/10.1016/j.cej.2020.124147

Manisha, Yadav SK (2017) Technological advances and applications of hydrolytic enzymes for valorization of lignocellulosic biomass. Bioresource Technology 245:1727 - 1739 doi:https://doi.org/10.1016/j.biortech.2017.05.066

Qi N, Hu X, Xin X, Ye S, Fu Z, Zhao X (2020) Mechanisms of biohydrogen recovery enhancement from peanut shell by $\mathrm{C}$. guangxiense: Temperature pretreatment ranges from -80 to $100{ }^{\circ} \mathrm{C}$. Bioresource Technology doi:10.1016/j.biortech.2020.123026

Rempel A, Machado T, Treichel H, Colla E, Margarites AC, Colla LM (2018) Saccharification of Spirulina platensis biomass using free and immobilized amylolytic enzymes. Bioresource Technology 263:163 - 171 doi:https://doi.org/10.1016/j.biortech.2018.04.114

Sawatdeenarunat C et al. (2016) Anaerobic biorefinery: Current status, challenges, and opportunities. Bioresour Technol 215:304-313 doi:10.1016/j.biortech.2016.03.074

Segal L, Creely JJ, Martin AE, Conrad CM (1959) An Empirical Method for Estimating the Degree of Crystallinity of Native Cellulose Using the X-Ray Diffractometer. Textile Research Journal 29:786-794 doi:10.1177/004051755902901003

Sindhu R, Binod P, Pandey A (2016) Biological pretreatment of lignocellulosic biomass--An overview. Bioresour Technol 199:76-82 doi:10.1016/j.biortech.2015.08.030

Smichi N, Messaoudi Y, Ksouri R, Abdelly C, Gargouri M (2014) Pretreatment and enzymatic saccharification of new phytoresource for bioethanol production from halophyte species. Renewable Energy 63:544-549 doi:10.1016/j.renene.2013.10.016

Wang D et al. (2018) Can hydrothermal pretreatment improve anaerobic digestion for biogas from lignocellulosic biomass? Bioresour Technol 249:117-124 doi:10.1016/j.biortech.2017.09.197

Wang J et al. (2019) Delignification overmatches hemicellulose removal for improving hydrolysis of wheat straw using the enzyme cocktail from Aspergillus niger. Bioresour Technol 274:459-467 doi:10.1016/j.biortech.2018.12.029

Wang Q, Fujisaki K, Ohsumi Y, Ogawa HIJEL (2001) Enhancement of dewaterability of thickened waste activated sludge by freezing and thawing treatment. 36:1361-1371

Yang Q, Pan XJ (2016) Correlation Between Lignin Physicochemical Properties and Inhibition to Enzymatic Hydrolysis of Cellulose. Biotechnology and Bioengineering 113:1213-1224

Zhang $\mathrm{T}$ et al. (2020a) Effects of different pretreatment methods on the structural characteristics, enzymatic saccharification and photo-fermentative bio-hydrogen production performance of $\begin{array}{llll}\text { corn } & \text { straw. } & \text { Bioresource } & \text { Technology }\end{array}$ doi:https://doi.org/10.1016/j.biortech.2020.122999

Zhang Y, Li T, Shen Y, Wang L, Zhang H, Qian H, Qi X (2020b) Extrusion followed by ultrasound as a chemical-free pretreatment method to enhance enzymatic hydrolysis of rice hull for fermentable sugars production. Industrial Crops and Products 149 doi:10.1016/j.indcrop.2020.112356

Zhao A, Yu L, Yang M, Wang C, Wang M, Bai X (2018) Effects of the combination of freeze-thawing and enzymatic hydrolysis on the microstructure and physicochemical properties of porous corn starch. Food Hydrocolloid 83:465-472 doi:10.1016/j.foodhyd.2018.04.041 
429

430

431

432

433

434
Zhao D et al. (2017) Exploring crystalline structural variations of cellulose during pulp beating of tobacco stems. Carbohyd Polym 174:146-153 doi:10.1016/j.carbpol.2017.06.060

Zheng Y, Zhao J, Xu F, Li Y (2014) Pretreatment of lignocellulosic biomass for enhanced biogas production. Progress in Energy and Combustion Science 42:35-53 doi:10.1016/j.pecs.2014.01.001 


\section{Supplementary Files}

This is a list of supplementary files associated with this preprint. Click to download.

- highlights.docx 